\title{
AGROTÓXICOS COMO TEMA GERADOR NO PROCESSO DE APRENDIZAGEM DE QUÍMICA
}

\author{
Rosana Lima Gerpe \\ Priscila Tamiasso-Martinhon \\ Jussara Lopes Miranda
}

\section{Introdução}

O ensino de química não pode continuar dissociado das questões vivenciadas em nosso século. Ele precisa ampliar o seu diálogo com a sociedade, não só no âmbito local, mas também no global e planetário. Partindose da premissa que a química está na vida, ela deve ser viva, o que implica um entrelaçamento com as inquietudes sociais, ambientais, históricas, culturais e psicológicas da espécie humana e de tudo com o qual ela se relaciona. Temas como os agrotóxicos, por exemplo, podem e devem ser geradores de processos argumentativos nas aulas de química, ou em palestras, seminários de divulgação científica, assim como nos espaços não-formais.

Neste capítulo, propõe-se a abordagem de agrotóxicos começando nos espaços formais das aulas de química, correlacionando-os com o conteúdo programático previsto e demandado pelas instâncias educacionais. 
Assim, a abordagem sobre a visão tridimensional de compostos químicos, por exemplo, que é de difícil compreensão para a maioria dos iniciantes em química, em especial os alunos do ensino médio (SILVA et al., 2019), foi dinamizada e contextualizada com a temática agrotóxicos.

No entanto, a proposta não se restringe à associação simplista entre modelos tridimensionais e moléculas de agrotóxicos, mas se baseia em primeiro plano, na problematização e significação deste tema e de suas reflexões e entrelaces com outras questões como o das queimadas, o emprego excessivo de fertilizantes, o desgaste e mau uso do nosso solo.

Propõe-se aos docentes, assim como aos seus alunos, um processo reflexivo para a (re) significação de suas práxis: uma maior proximidade da construção compartilhada do conhecimento, que será mediada por atividades com o protagonismo discente, empregando materiais de baixo custo, recicláveis e de fácil manuseio, realizadas em grupos para fomentar a aprendizagem cooperativa.

A problematização sobre o tema agrotóxicos será abordada inicialmente, seguida do detalhamento de como este trabalho foi desenvolvido no ensino de química, em escolas do ensino médio, tanto regular como para jovens 
e adultos, e no primeiro período do ensino de graduação para a licenciatura em química.

\section{A pandemia e o aumento das queimadas no Brasil}

A abordagem temática sobre os agrotóxicos no ensino de química não pode estar descontextualizada do uso atual do solo, especialmente, em nosso país. Assim, o manejo inapropriado do solo, empregando-se queimadas para a sua "limpeza", acaba refletindo em um processo de maior esgotamento, que exigirá cada vez mais quantidades de fertilizantes e agrotóxicos para a realização do cultivo (DE AZEVEDO; MASCARENHAS, 2020, p. 275).

Segundo os dados de satélite publicados pelo Instituto Nacional de Pesquisas Espaciais (INPE), até o início de novembro de 2020 foram identificados mais de 16 mil queimadas no estado do Amazonas, ultrapassando cerca de 30\% do total de focos registrados em todo ano de 2019, o que reflete uma grave situação em nosso país (BRASIL, 2020). O crescimento dos focos de queimadas nos últimos três anos não se restringe à Amazônia, mas inclui outros biomas brasileiros como pode ser evidenciado na Tabela 1. A realidade do Pantanal, que teve um aumento histórico em 2020, é tão grave que chega a ser criminosa, conforme ilustra a Figura 1 (INPE, 2020). 
Tabela 1: Quantitativo de focos de queimadas, em diferentes biomas brasileiros, durante o período de 2012 até 08/11/2020

\begin{tabular}{lccccccccc}
\hline & $\mathbf{2 0 1 2}$ & $\mathbf{2 0 1 3}$ & $\mathbf{2 0 1 4}$ & $\mathbf{2 0 1 5}$ & $\mathbf{2 0 1 6}$ & $\mathbf{2 0 1 7}$ & $\mathbf{2 0 1 8}$ & $\mathbf{2 0 1 9}$ & $\mathbf{2 0 2 0}$ \\
\hline Amazônia & 86719 & 58688 & 82554 & 106438 & 87761 & 107439 & 68345 & 89176 & 95013 \\
& & & & & & & & & \\
Pantanal & 7447 & 3396 & 1567 & 4458 & 5184 & 5773 & 1691 & 10025 & 21713 \\
& & & & & & & & & \\
Cerrado & 90600 & 44017 & 65871 & 75094 & 58833 & 66762 & 39449 & 63874 & 59896 \\
Caatinga & 16717 & 9859 & 9496 & 15133 & 13593 & 11004 & 11347 & 14960 & 10161 \\
& 1053 & 801 & 708 & 730 & 1327 & 936 & 742 & 1420 & 1610 \\
Pampa & 14702 & 11388 & 15704 & 14929 & 17520 & 15597 & 11298 & 18177 & 16792 \\
$\begin{array}{l}\text { Mata } \\
\text { Atlântica }\end{array}$ & & & & & & & & & \\
\hline
\end{tabular}

Fonte: Adaptado de INPE (2020)

Figura 1: Quantitativo de focos de queimadas no Pantanal durante o período de 1998 até 08/11/2020.

25.000

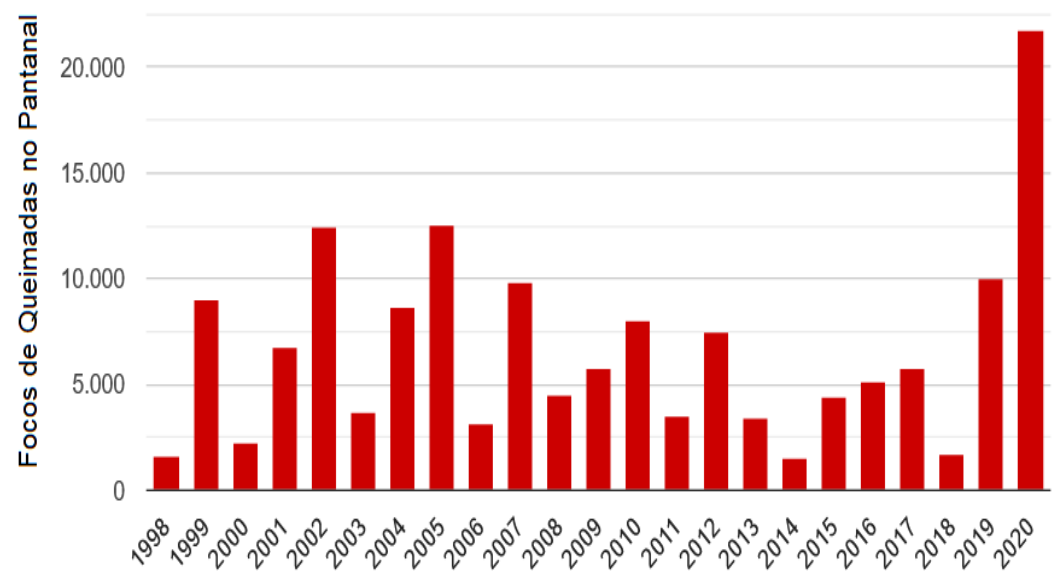

Fonte: Adaptado de INPE (2020) 
A Figura 1 confirma que o índice dos focos de queimadas no Pantanal mais que dobrou, antes mesmo do término de 2020.

Infelizmente, as queimadas ainda representam uma técnica muito empregada no Brasil. Contudo, quando realizadas sem controle representam crime ambiental, o que torna seu infrator sujeito a sanções penais (DE SOUSA; BASTOS, 2020). Na Figura 2, observa-se o grau de alastramento das queimadas em todo o país, mesmo em um ano de pandemia, como foi o de 2020 (BRASIL, 2020, p. 3).

Figura 2: Focos de queimadas no Brasil registradas durante os meses de outubro, setembro e agosto de 2020.
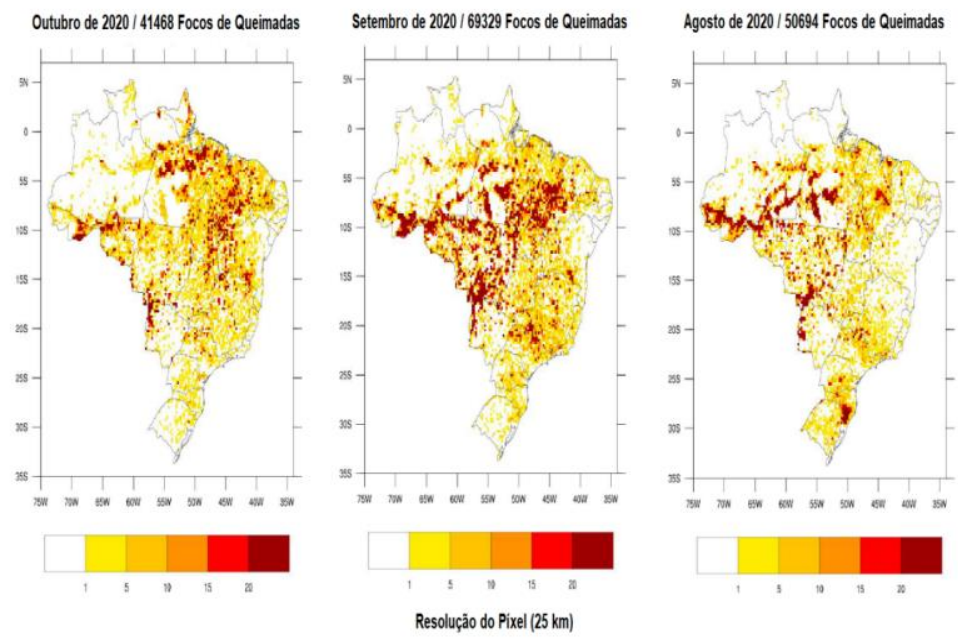

Fonte: Adaptado de Brasil (2020) 
As informações apresentadas na Figura 2 foram obtidas pelo satélite de monitoramento AQUA (Aqua Project Science) - da NASA (National Aeronautics and Space Administration) - e evidenciam a distribuição espacial dos focos de queimadas no Brasil durante os meses de outubro, setembro e agosto de 2020. As maiores concentrações de queimadas em outubro aconteceram nas regiões Centro-Oeste, Nordeste e Sudeste - com destaque para os estados de Rondônia, Acre, Pará e Tocantins totalizando mais de 40 mil detecções de incêndio em todo o país (BRASIL, 2020, p. 3a). Em setembro, esse quantitativo quase atingiu 70 mil focos, apresentando uma maior taxa no Centro-Oeste e na Amazônia Legal (BRASIL, 2020, p. 3b) e no mês anterior, os maiores índices forma no Sul, Centro-Oeste e Amazônia Legal (BRASIL, 2020, p. 3c).

\section{O esgotamento do solo e o aumento do uso de agro- tóxicos}

Há, portanto, uma relação intrínseca entre as queimadas e a maior necessidade de fertilizantes, em função do empobrecimento do solo, que causa uma séria ruptura no equilíbrio existente no ecossistema, acarretando uma maior proliferação de pragas e insetos, o que desencadeia o uso de agrotóxicos em maior quantidade, gerando um ciclo vicioso e pernicioso (Figura 3). No Brasil, de acordo com os dados do Instituto de Pesquisas 
Econômica e Aplicada (IPEA), temos observado uma expansão do uso de agrotóxicos (áreas total e de lavoura dos estabelecimentos), associada a uma diminuição das áreas de agricultura familiar, com o agravante do aumento do uso de agrotóxicos também nestes tipos de cultivo (IPEA, 2020).

Desde 2008, o Brasil está classificado como o maior consumidor de agrotóxicos do mundo (IPEA, 2020) e, de acordo com o Programa de Análise de Resíduos de Agrotóxicos em Alimentos (PARA) ${ }^{1}$, as análises mostram que $23 \%$ dos alimentos de origem vegetal consumidos pela população brasileira estão inconformes em relação à quantidade de agrotóxicos presentes. Mais agravante ainda foram os resultados das análises de alimentos como abacaxi, laranja, batata doce, goiaba e uva, que indicaram o risco agudo na concentração de agrotóxicos, implicando em um potencial prejuízo à saúde em uma única exposição, refeição ou ao longo do dia (ANVISA, 2020).

Na tabela 2 são apresentados os ingredientes ativos mais usados para a formulação dos agrotóxicos no Brasil, destacando-se o glifosato (ácido N-fosfonometil 2-aminoacético) e o 2,4 D (ácido 2,4 diclorofenoxiacético) (IPEA, 2020b). No quadro 1 são apresentadas as fórmu-

${ }^{1}$ Plano plurianual 2017-2020 - resultados do $1^{\mathrm{o}}$ Ciclo 2017-2018 (ANVISA, 2020). 
las estruturais destes dois ingredientes ativos, mais as do Mancozebe, um ditiocarbamado muito utilizado, além do DDT- 1-cloro-4-[2,2,2-tricloro-1,4-clorofenil)etilbenzeno) que já foi empregado e banido, sendo importante na contextualização histórica dos agrotóxicos.

Figura 3: Ciclo de esgotamento do solo.

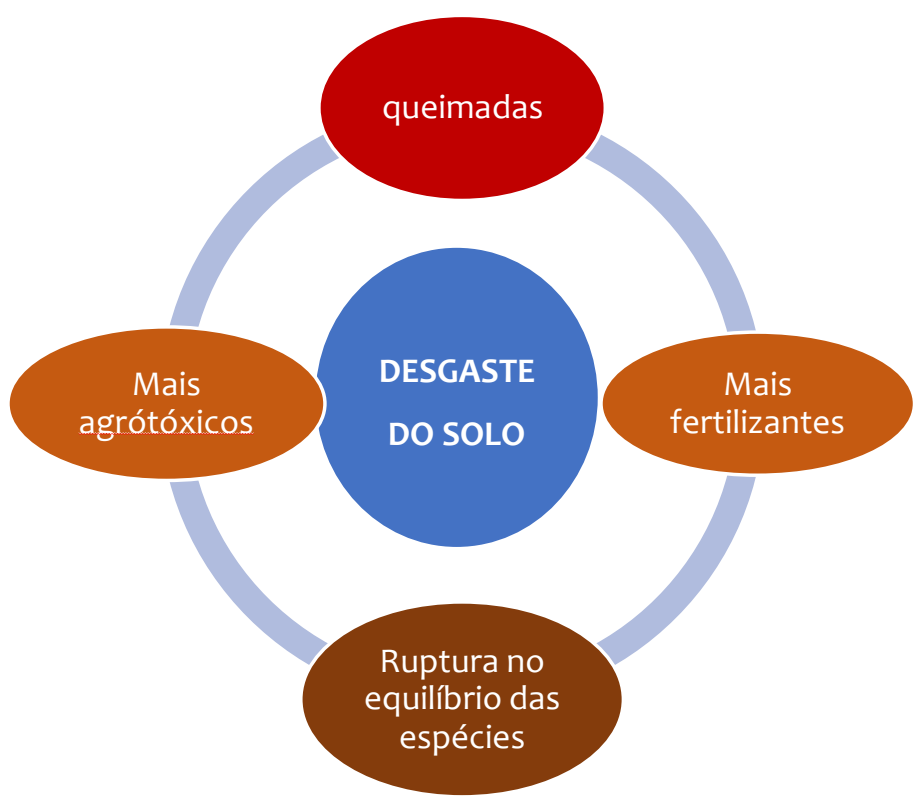

Fonte: Elaborado pelas autoras 
Tabela 2: Princípios ativos dos agrotóxicos mais usados no Brasil Uso de pesticidas: quantidade total, por ingrediente ativo (2017)

\begin{tabular}{|c|c|c|c|c|}
\hline Ingrediente ativo & Classificaç̧ăo toxicológica & Periculosidade ambiental & $\begin{array}{l}\text { Quantidade } \\
\text { (1 mil toneladas) }\end{array}$ & Percentual \\
\hline Glifiosato & IV & $\|$ & 173 & $32,1 \%$ \\
\hline $2,4 \cdot D$ & 1 & ॥I & 57 & $10,6 \%$ \\
\hline Mancozebe & I & $\| 11$ & 31 & $5,7 \%$ \\
\hline Acefato & $\|$ & $\|$ & 27 & $5,0 \%$ \\
\hline Óleo mineral & NV & IV & 27 & $5,0 \%$ \\
\hline Atraina & $\| 11$ & $\|$ & 25 & $4,6 \%$ \\
\hline Olleo vegetal & IV & IV & 13 & $2,5 \%$ \\
\hline Paraquate (dicloreto) & । & $\| 11$ & 12 & $2,2 \%$ \\
\hline Imiddadopido & $\|$ & $\| 11$ & 9 & $1,7 \%$ \\
\hline Oxicloreto de cobre & 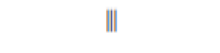 & $\|$ & 1 & $1,4 \%$ \\
\hline Outros & . & . & 158 & $29,3 \%$ \\
\hline Total & . & . & 540 & . \\
\hline
\end{tabular}

Fonte: bama. Dados coletados em;: 〈hitps:/lbitly/326uEx/s.

Obs: I. Classificą̧io towicológica (Agéncia Nacional de Vigiläncia - Anvisa): extremamente tóxico (I), altamente tóico (II), medianamente tóxico (III) e pouco tóxico (IV). 2. Periculosidade ambiental (lbama): altamente perigoso (I), muito perigoso (II), perigoso (III) e pouco perigoso (IV).

Fonte: IPEA, 2020b. 
Quadro 1: Fórmulas estruturais dos ingredientes ativos dos agrotóxicos

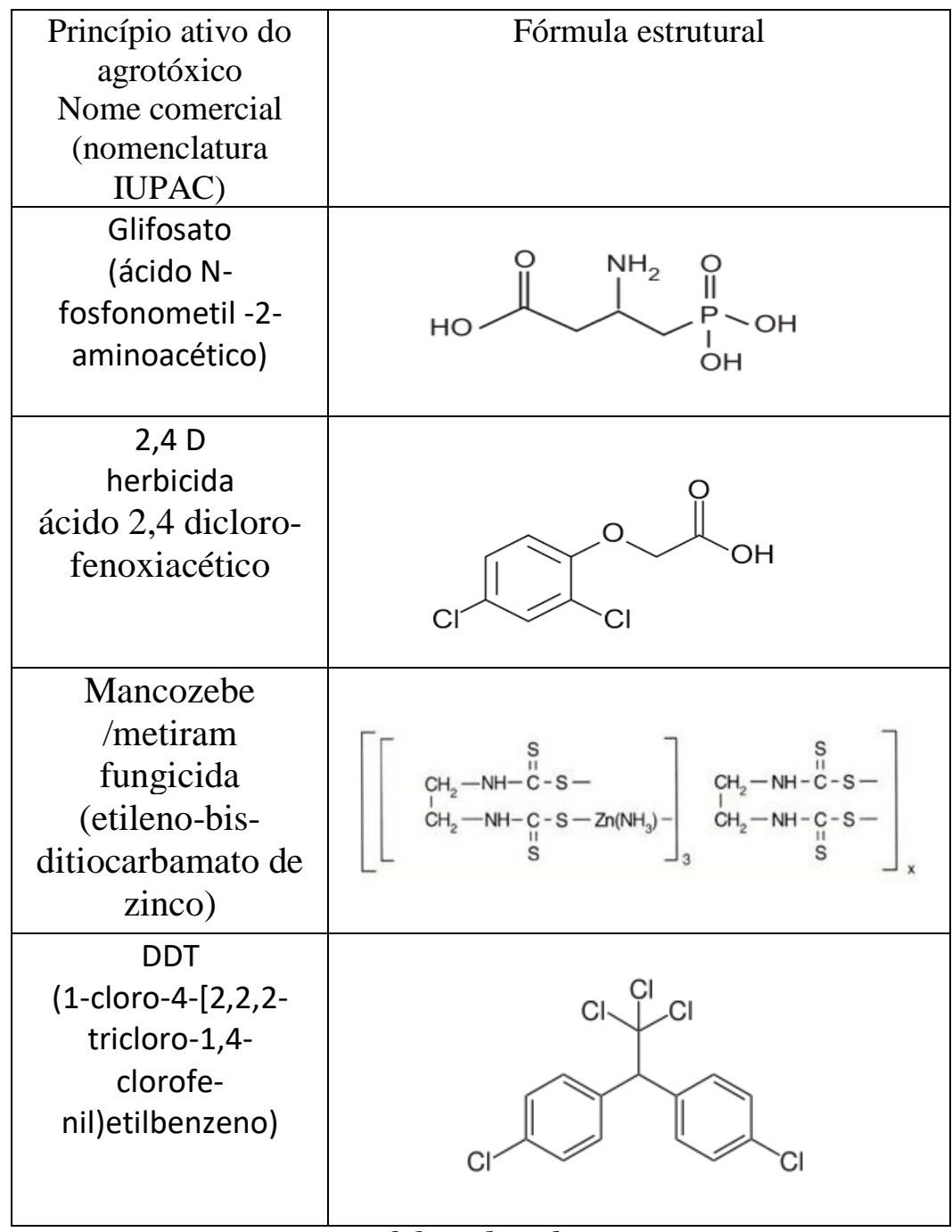

Fonte: Elaborado pelas autoras 
No entanto, já existem opções para se quebrar o ciclo de esgotamento do solo, como ilustra a Figura 3, diminuindo gradativamente, ou totalmente, o emprego de agrotóxicos na produção de alimentos de origem vegetal. A Empresa Brasileira de Pesquisa Agropecuária (Embrapa) tem desenvolvido o manejo integrado de pragas (MIP) em diferentes tipos de cultivo, que é uma concepção integrativa, que emprega técnicas e procedimentos ecológicos para controlar naturalmente a população de pragas.

O manejo integrado de pragas (MIP) é uma filosofia de controle de pragas que procura preservar e/ ou incrementar os fatores de mortalidade natural, por meio do uso integrado de todas as técnicas de combate possíveis e disponíveis, selecionadas com base em parâmetros ecológicos, econômicos e sociológicos. Visa, ainda, manter os níveis populacionais dessas pragas abaixo do nível de dano econômico (NDE), por meio da utilização simultânea de diferentes técnicas ou táticas de controle, de forma econômica e harmoniosa com o ambiente. (EMBRAPA, 2020, p. 2)

No contexto do MIP, só é considerado praga aquilo que venha a causar danos econômicos. Este sistema também é conhecido como manejo ecológico de pragas (MEP) e manejo agroecológico de pragas (MAP). 
Certamente, este contexto e suas implicações devem ser discutidos em sala de aula, propiciando reflexões críticas a partir de seu entrelaçamento com o aprendizado de Química, tanto em espaços formais, quanto nãoformais. Afinal, o direito ambiental precisa ser compreendido como um direito da humanidade, e tais assuntos precisam ser discutidos em sala de aula.

\section{A educação ambiental como processo reflexivo com os referenciais freireanos}

A interdisciplinaridade, assim como a criticidade, propostas por Freire, estabelecem um rico diálogo com a educação ambiental, na sua perspectiva crítica, que é abrangente, dialógica, inserida no campo da reflexão da realidade posicionada historicamente, geograficamente, ontologicamente e na práxis resultante deste processo reflexivo.

A superação e não a ruptura se dá na medida em que a curiosidade ingênua, sem deixar de ser curiosidade, pelo contrário, continuando a ser curiosidade, se criticiza. Ao criticizar-se, tornando-se então, permitome repetir, curiosidade epistemológica, metodicamente rigorizando-se na sua aproximação do objeto, conota seus achados com maior exatidão. (FREIRE, 2010, p. 31) 
A educação ambiental crítica é, portanto, assim como a educação deve ser, eminentemente política e dialógica, contextualizada na problematização da realidade, provocadora de inquietações mobilizadoras em prol de uma participação social e da cidadania indissociáveis à práxis socioambiental. Assim, o diálogo da interdisciplinaridade, não-dominante de um saber absoluto, mas solidário, reflexivo e crítico, como proposto por Freire, "cai como uma luva" nos pressupostos para uma educação ambiental crítica, que pode e deve estar presente nas discussões temáticas do ensino de química (MIRANDA, 2017/ 2018/ 2019/ 2020; GERPE, 2019c).

\section{O desafio da complexidade da COVID-19 e Morin}

Nada mais atual para os tempos de pandemia vivenciada atualmente que o paradigma da complexidade proposto por Morin (1996), ou seja, é preciso resgatar a perspectiva que nossa realidade, assim como o conhecimento gerado por nós, é complexa, tecida e influenciada por todos os aspectos vinculados ao meio que estamos inseridos (lugar geográfico, químico, biológico, histórico e social). Para nos prepararmos melhor para os desafios reais que temos e teremos e o novo vírus SARS-COV 2 é um exemplo disto, precisamos nos desvencilhar da fragmentação do ensino e consequentemente do próprio conhecimento humano. 
Complexus significa o que foi tecido junto; de fato, há complexidade quando elementos diferentes são inseparáveis constitutivos do todo (como o econômico, o político, o sociológico, o psicológico, o afetivo, o mitológico), e há um tecido interdependente, interativo e retroativo entre o objeto de conhecimento e seu contexto, as partes e o todo, o todo e as partes, as partes entre si. Por isso a complexidade é a união entre a unidade e a multiplicidade (...) A educação deve promover a 'inteligência geral' apta e referir-se ao complexo, ao contexto, de modo multidimensional e dentro da concepção global.

Não somos fragmentados e os nossos processos de ensino e aprendizagem também não podem ser. Queimadas, fertilizantes, agrotóxicos e pandemia são temáticas reais, que ocorrem juntas e misturadas, como é próprio da realidade planetária. E é esta perspectiva que devemos ensejar em nossos alunos, em nossas formas de aprender também com eles. Tecendo junto, pegando uma linha temática e relacionando com outra, e com outra, com a finalidade de nos aproximar mais do real para nos prepararmos melhor para ele.

\section{Metodologia}

O presente trabalho foi desenvolvido no espaço formal de escolas do município do Rio de Janeiro, em três âmbitos diferentes, a saber: Ensino Médio Regular 
(EMR), Ensino de Jovens e Adultos (EJA) e no curso de graduação em Licenciatura em Química, ocorridas no ano de 2018. As atividades foram divididas em dois Grupos Focais (GF), explicitados a seguir:

a) GF 1 - atividades lúdicas de moléculas tridimensionais de agrotóxicos desenvolvidas com uma turma de 35 alunos da EJA, terceiro ano do $2^{\circ}$ Semestre do ano de 2018, com idade entre 18 e 56 anos;

b) GF 2 - sondagem sobre a percepção do uso do solo através de questionários híbridos e experienciações imagéticas desenvolvidas com três grupos de alunos: uma turma de 30 alunos com idade entre 16 e 19 anos do ensino médio regular da 3 série (ano de 2018), outra turma de 24 alunos com idade entre 18 e 56 anos da EJA da 3 série e a terceira turma de 15 alunos com idade entre 18 e 30 anos do ensino superior do $1^{\circ}$ período da Licenciatura em Química (LQ).

Na sequência será descrito a sequência que foi desenvolvida para cada GF.

\section{Atividades lúdicas com modelos tridimensionais}

As atividades do grupo focal 1 foram divididas em 4 momentos, realizados em 2 tempos de 60 minutos cada. O momento 1 foi subdividido em 4 etapas: 
a) problematização/sensibilização com a temática agrotóxicos no âmbito de Química Orgânica em uma abordagem sociopolítica;

b) exposição dialógica/aula introduzindo a Química Orgânica, utilizando slides com as fórmulas estruturais dos agrotóxicos mais utilizados no Brasil;

c) contextualização da Química Orgânica com os agrotóxicos abordando a saúde do trabalhador rural e o consumidor;

d) reconhecimento de cadeias (quanto ao fechamento da cadeia, disposição dos átomos, tipos de ligação e natureza dos átomos), classificação quanto ao número de carbonos (primário, secundário, terciário e quaternário) e tipos de ligações químicas (simples, dupla, tripla, pi e sigma) usando as estruturas dos agrotóxicos (glifosato, DDT, 2,4 D, etc).

O momento 2 foi subdividido em 2 etapas: 
a) uma janela para o real: dinâmica envolvendo o documentário "O Veneno está na mesa $\mathrm{II}^{2}$ ", do diretor Sílvio Tendler, com duração de 1 h e 10 minutos.

b) roda de conversa mediada pela docente, levantando os temas relacionados a: saúde, política, economia e social.

O momento 3 foi realizado através da experiência - ação: "Dinâmica das Moléculas", na qual os alunos confeccionaram modelos tridimensionais de moléculas orgânicas do glifosato e do DDT com jujubas e palitos de dente. (GERPE, 2019d)

No momento 4, foram realizadas as seguintes ações: alfabetização e divulgação científica, quando os alunos trabalharam na análise do rótulo de agrotóxicos e na identificação de suas bulas, em função da classificação dos diferentes tipos de agrotóxicos. (GERPE, 2019a)

Neste capítulo, apresentaremos os resultados obtidos no momento 3 , no qual foi proposto aos alunos a construção de modelos tridimensionais das moléculas dos agrotóxicos, utilizando para as suas representações palitos de dente e jujubas, que funcionaram como alicer-

Disponível

em:

https://www.youtube.com/watch?time_continue $=12 \& v=$ fyvoKljtvG4 \&feature=emb_logo 
ces para o desenvolvimento do ensino-aprendizagem da Química.

Esta atividade também foi motivada pelas dificuldades relatadas pelos estudantes no aprendizado das representações tridimensionais das fórmulas estruturais das moléculas orgânicas, podendo ser inserida facilmente nas aulas do ensino médio (SILVA, 2017), já que contempla o seu conteúdo programático. Antes da confecção dos modelos tridimensionais foi abordado o conteúdo em duas aulas teóricas, apresentando as moléculas no modelo plano, assim como foi discutido o reconhecimento das funções orgânicas em produtos utilizados no cotidiano, como material de limpeza, alimentação, medicação, higiene e beleza.

A “construção" das moléculas e a sua visualização tridimensional contribuem para facilitar o entendimento do aluno sobre a formação de cadeias carbônicas, assim como os tipos de cadeias carbônicas, os diferentes tipos de ligações químicas e a presença de grupos funcionais específicos.

Para confecção dos átomos de carbono, foram utilizadas jujubas vermelhas, e para os átomos de hidrogênio, jujubas verdes. Como os átomos de carbono e hidrogênio possuem tamanhos diferentes, a professora explicou a importância do raio atômico, associado às propriedades periódicas destes dois elementos. As ligações 
químicas foram representadas com os palitos entre os átomos fixados nas jujubas. Nas estruturas que representam as moléculas dos alcanos, formadas somente por ligações simples, os átomos foram ligados entre si com 1 palito entre os carbonos; nas que representam os alcenos, 2 palitos e para as que representam as moléculas dos alcinos, 3 palitos entre os carbonos. Pôde-se discutir também as diferenças nas distâncias e energias das ligações simples, duplas e triplas.

\section{Percepção sobre o solo e experienciações imagéti- cas}

Nesta atividade, foi elaborado um questionário híbrido, contemplando a solicitação da expressão imagética sobre o tema. Explicitaremos, neste trabalho, algumas destas representações feitas por estudantes dos três segmentos participantes, a partir da pergunta 10 presente na figura 42 . A análise das demais questões da figura 4 podem ser encontradas em Gerpe (2019b). 
Figura 4: Questionário para avaliar a percepção do uso sustentável do solo

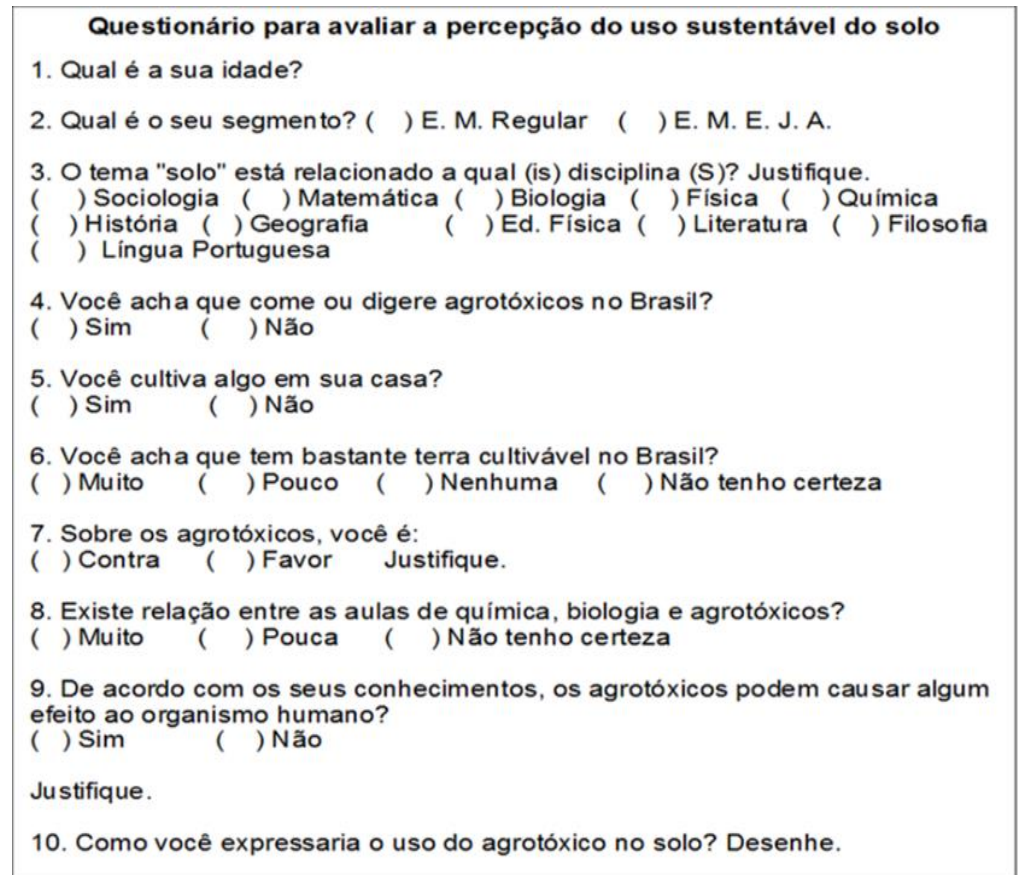

Fonte: Autoria própria

Um desenho pode tornar visíveis aspectos difíceis de serem entendidos pelos alunos através da linguagem verbal. Além disso, a análise dos desenhos acontece através da diferenciação dos aspectos genéricos e específicos do conteúdo informacional selecionado.

Os parâmetros selecionados para a análise preliminar dos desenhos são apresentados no Quadro 4 e pretendem sinalizar a formação conceitual de agrotóxicos, 
assim como os "caminhos sociais" e a sua dimensão temporal.

Quadro 2: Parâmetros escolhidos para a análise das expressões imagéticas dos alunos

\begin{tabular}{|lc|}
\hline Parâmetro & Associação \\
\hline O que? & veneno x fertilizantes \\
Onde? & plantio, campo, alimentos consumidos, rio, solo... \\
Como? & o agrotóxico chega até nós \\
Quando? & dimensão temporal \\
\hline
\end{tabular}

Fonte: Autoria própria

\section{Resultados relevantes}

Os modelos $3 \mathrm{D}$, das moléculas confeccionadas pelos alunos do Ensino Médio Regular (EMR) com material de baixo custo, podem ser visualizados na Figura 5 .

Figura 5: Modelos tridimensionais feitos com materiais de baixo custo pelos alunos do EMR.

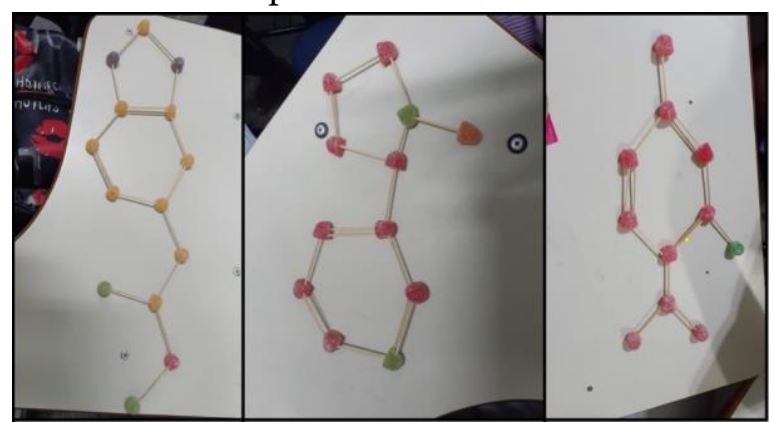

Fonte: Acervo pessoal das autoras 
A construção das moléculas tridimensionais foi de fácil implemento e de gasto de tempo mínimo, o que facilitou seu uso na sala durante as aulas. Além disso, o material é de baixo custo, fácil acesso e possibilita que a estrutura fique estável, o que permite a observação e o entendimento do conteúdo pelo aluno.

Ao longo do trabalho, observamos a importância da confecção de modelos tridimensionais nas aulas de Química Orgânica também como aspecto motivacional e interacionista, pois propiciou o trabalho e debates em grupos.

A ferramenta utilizada pelos alunos fez com que eles tivessem um papel ativo na construção de seu conhecimento. O professor atuou como mediador, auxiliando os alunos na resolução de problemas através do questionamento, direcionando-os à aprendizagem do conteúdo de forma significativa e associando a curiosidade à reflexão.

Em relação ao diálogo entre a Química Orgânica e a Educação Ambiental Crítica, os alunos passaram a refletir e compreender como agem as interações entre os elementos químicos, como seus simples atos do cotidiano afetam o meio ambiente. Ressaltaram como é importante que cada um faça sua parte, para que o individual se modifique no coletivo, e assim pequenas atitudes tomem grandes magnitudes. 
Para Chassot (1993), a Química que se ensina deve ser ligada à realidade. Entretanto, os exemplos que são apresentados aos estudantes geralmente estão desvinculados do cotidiano discente. Nesse sentido, Santos e Schnetzler (1996) constataram a importância dos temas químicos sociais, que visam efetivar a contextualização dos conteúdos programáticos. Assim, ao mesmo tempo que o aluno entra em contato com o seu cotidiano, ele pode perceber como tudo está conectado com a sua vida, sua saúde, com o bem-estar dos outros e ao seu pertencimento planetário consciente. Nessa perspectiva, o aluno é levado à reflexão sobre a responsabilidade que todos nós devemos ter como agentes ativos na sociedade, em relação às questões ambientais e aos posicionamentos sociopolíticos inerentes às desigualdades sociais e exploratórias.

A estratégia didática utilizada exigiu uma participação ativa dos estudantes nos seus processos de aprendizagem, pois a professora motivou-os a socializarem suas ideias e valorizou suas participações. Os estudantes compartilharam informações com os colegas e construíram conceitos colaborativamente. A avaliação das atividades desenvolvidas mostrou que a temática "agrotóxicos" contribuiu para a associação entre os conceitos científicos e o cotidiano discente, que foi enriquecida pela problematização de como os agrotóxicos podem chegar na mesa dos brasileiros e extrapolada nas discussões realizadas em sala de aula (Figura 6). 
Figura 6: Elaboração de modelos tridimensionais de princípios ativos dos agrotóxicos.

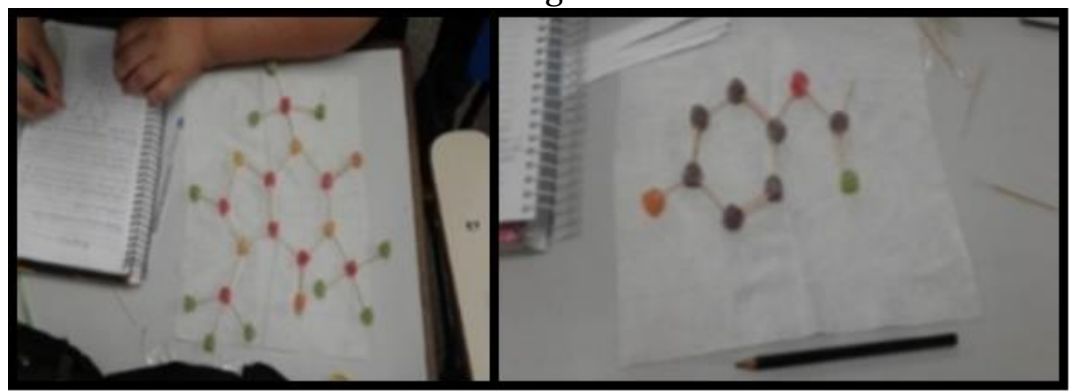

Fonte: Acervo pessoal das autoras

A segunda etapa do trabalho foi a análise dos desenhos realizados pelos alunos, e alguns desses resultados foram apresentados no Workshop Educação Ambiental e o Ensino de Química, WEAQ 2019 (GERPE et al., 2019).

A partir da análise dos desenhos produzidos pelos alunos, foram obtidos os resultados conforme a grade documentária do desenho aqui representado: Como você expressaria o uso do agrotóxico no solo? Desenhe.

Os conteúdos expostos em sala de aula pelo docente, seja utilizando imagens ou transmitindo oralmente, nem sempre são compreendidos pelo aluno; ou seja, a transposição didática pode ser ineficiente. Nesse contexto, o docente precisa considerar que cada aluno possui uma forma cognitiva de entender conceitos e estruturar suas ideias, como pode ser evidenciado a partir das expressões imagéticas elaboradas pelos alunos do EMR (Fi- 
gura 7), da EJA (Figura 8) e da Licenciatura em Química (Figura 9), bem como pela análise destas (Quadro 3). Nas figuras 7, 8 e 9 foram adicionadas nuvens de palavras referentes às expressões mais citadas nos desenhos feitos.

Figura 7: Expressões imagéticas elaboradas por alunos do EMR, após provocações sobre o emprego de agrotóxicos e nuvem feita pelas autoras com as palavras presentes nos desenhos.

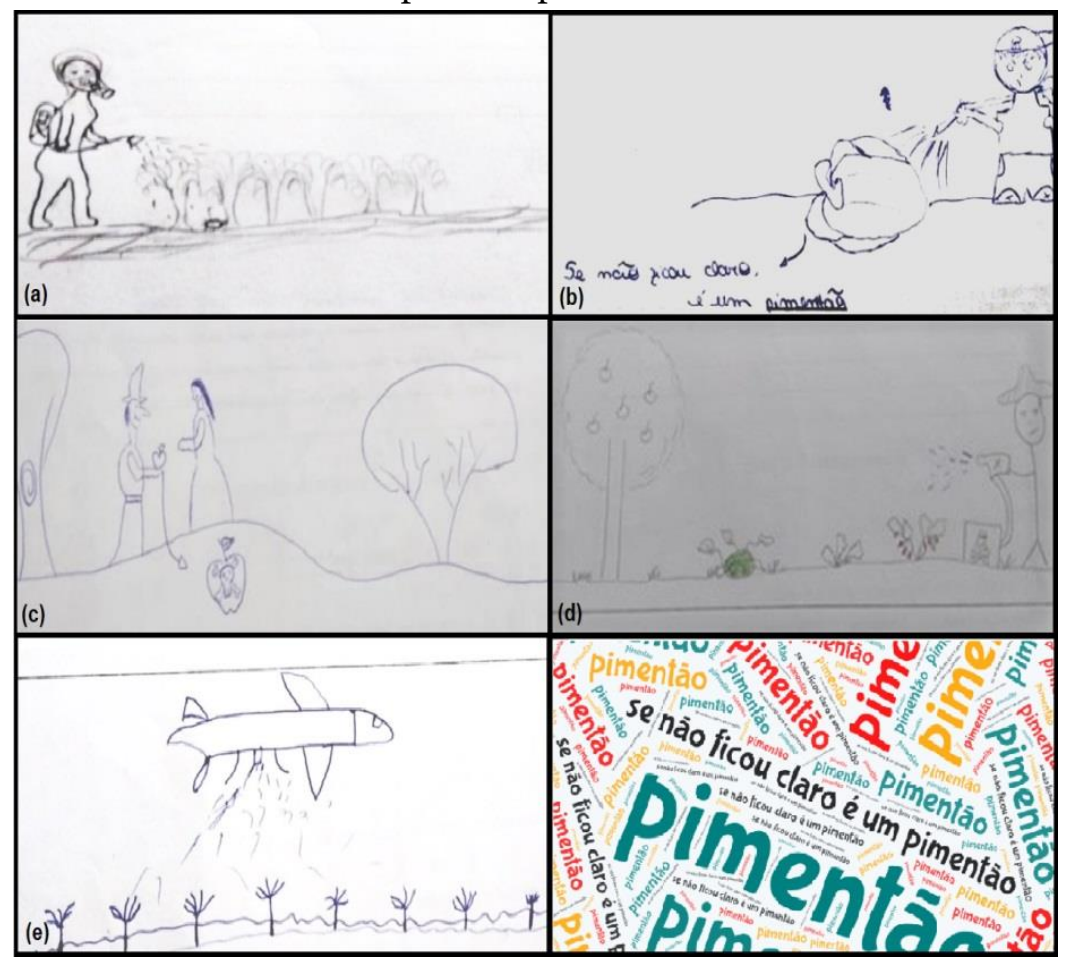

Fonte: Acervo pessoal das autoras 
Figura 8: Expressões imagéticas elaboradas por alunos da EJA, após provocações sobre o emprego de agrotóxicos e nuvem feita pelas autoras com as palavras presentes nos desenhos.

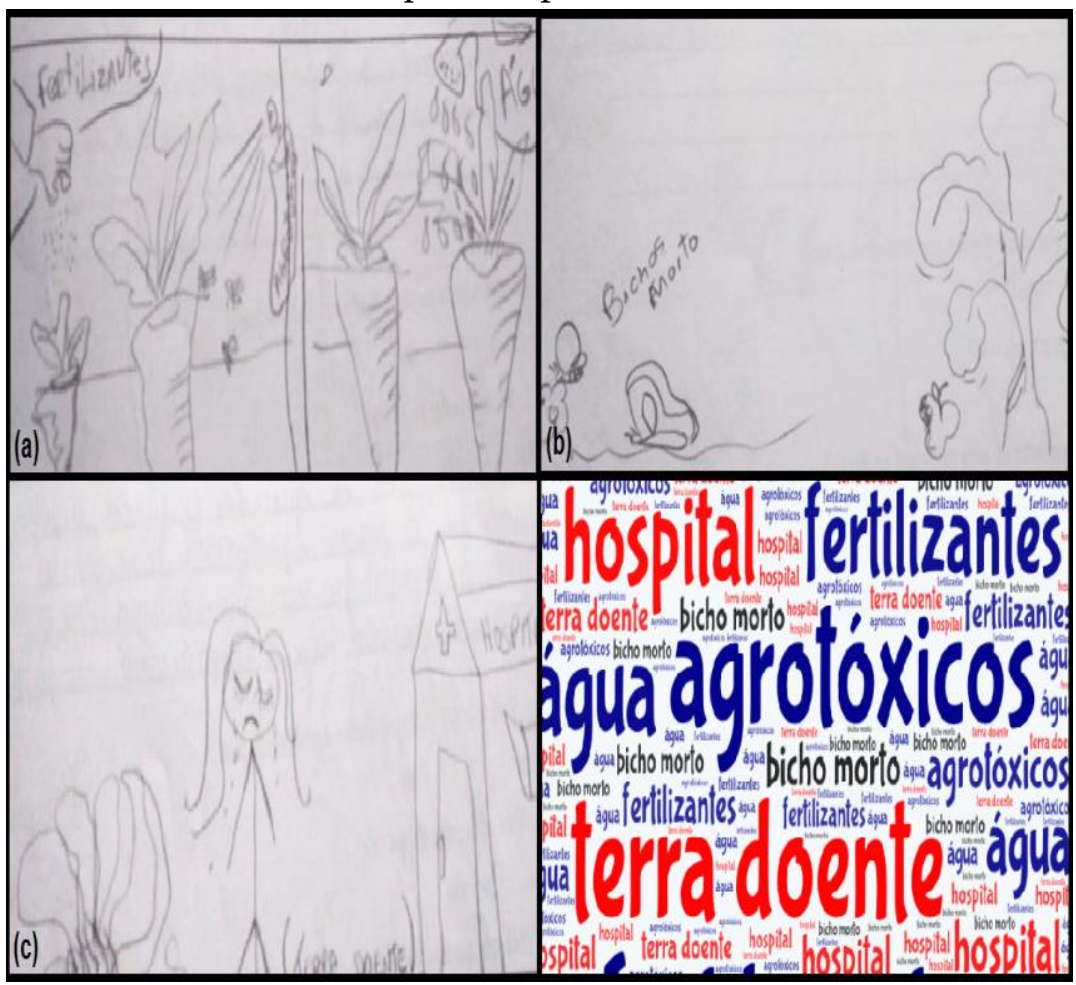

Fonte: Acervo pessoal das autoras 
Figura 9: Expressões imagéticas elaboradas por Licenciandos em Química (UFRJ), após provocações sobre o emprego de agrotóxicos e nuvem feita pelas autoras com as palavras presentes nos desenhos.

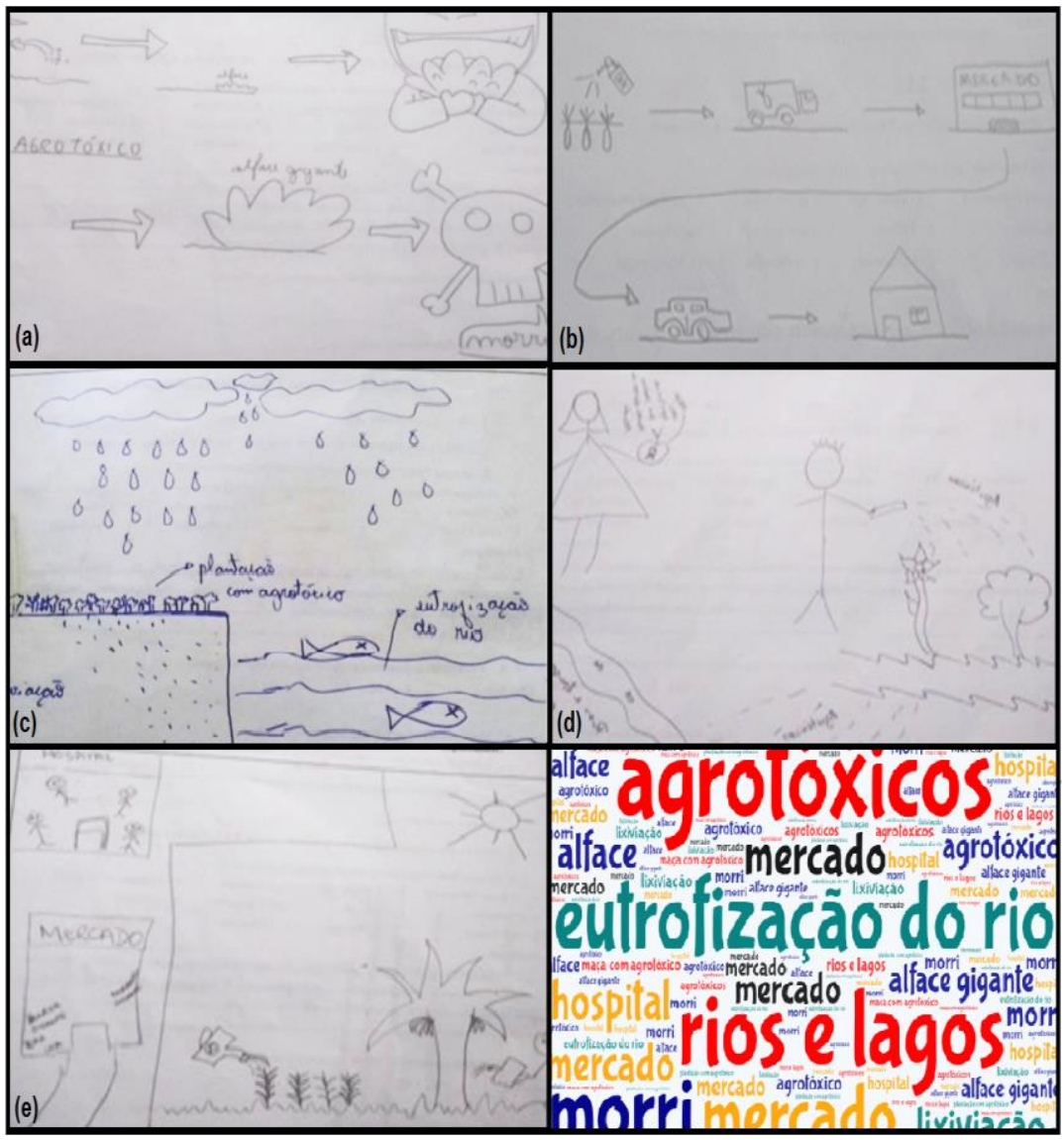

Fonte: Acervo pessoal das autoras 
Quadro 3: Síntese da análise imagética

\begin{tabular}{|lccc|}
\hline & \multicolumn{3}{c|}{ Figuras } \\
Parâmetro & EMR & EJA & LQ \\
\hline O que? & $6 \mathrm{~b}$ & $7 \mathrm{~b} ; 7 \mathrm{c}$ & $8 \mathrm{a} ; 8 \mathrm{c} ; 8 \mathrm{~d}$ \\
Onde? & & & $8 \mathrm{~b}, 8 \mathrm{c}$ \\
Como? & $6 \mathrm{a} ; 6 \mathrm{~b} ; 6 \mathrm{~d}, 6 \mathrm{e}$ & & \\
Quando? & & & $8 \mathrm{a} ; 8 \mathrm{c}$ \\
$\begin{array}{l}\text { Distorções } \\
\text { Conceituais }\end{array}$ & $6 \mathrm{~b} ; 6 \mathrm{~d}$ & $7 \mathrm{a}$ & $8 \mathrm{~d}$ \\
\hline
\end{tabular}

Fonte: Autoria própria

Ao analisar os desenhos notamos algumas semelhanças entre os estudantes participantes da pesquisa em relação à concepção do agrotóxico associada à ideia de veneno, assim como o combate às pragas e ao aumento da demanda de produtividade. $\mathrm{O}$ uso excessivo e incorreto de agrotóxicos e suas consequências negativas ao ecossistema, ao meio ambiente e saúde humana foram identificados nos desenhos elaborados por alunos do EMR (Figura 7 b), da EJA (Figuras 8 b e 8 c) e da Licenciatura em Química (Figuras 9a, 9c e 9d).

A partir das representações imagéticas também foi possível verificar que, apesar desta temática ser bem difundida pelo senso comum dos alunos participantes, ainda há muitas dúvidas e distorções conceituais sobre ela. Observamos erros conceituais em ambos os segmentos, um exemplo disto pôde ser observado nas expressões imagéticas discentes, em que alguns alunos confundiram 
agrotóxicos com fertilizantes, ao desenhar o crescimento dos vegetais em tamanho anormal (Figuras $7 \mathrm{~b}, 7 \mathrm{~d}, 8 \mathrm{a}$ e 9d).

Assim, na análise do significado dos agrotóxicos na representação imagética dos alunos, a observação de construção de significados distorcidos ou errôneos nos mostra a relevância que o assunto agrotóxico representa, sendo um tema pertinente à realidade atual brasileira $\mathrm{e}$ por isso, muito importante para a abordagem no ensino de química.

Ao analisarmos "o onde?" observamos o pertencimento territorial associado aos agrotóxicos, onde os alunos participantes deste trabalho "localizam" os agrotóxicos, perto ou distanciados deles. A maioria dos desenhos "localizou" os agrotóxicos no campo, com o plantio. Contudo, o autor da Figura 9b explicitou o caminho percorrido pelo emprego dos agrotóxicos no campo, até o mercado consumidor, estabelecendo a conexão entre plantio, uso de agrotóxicos e consumo de alimentos. $\mathrm{Na}$ Figura 8b, o pertencimento territorial do tema agrotóxicos se encurta, se torna mais próximo e isto pode fazer muita diferença na discussão sobre o tema.

Quanto à análise de como os agrotóxicos chegam até nós, foi possível observar nas Figuras $7 \mathrm{a}, 7 \mathrm{~b}$ e $7 \mathrm{~d}$ a representação da aplicação do agrotóxico por um agricultor, e na Figura 7e através da dispersão aérea, sendo esta 
última forma uma prática muito comum em nosso país (FERREIRA, 2015). Observa-se, além disso, a diferença quanto ao uso de equipamentos de segurança individuais entre o agricultor que aplica o agrotóxico sem proteção (Figuras $7 \mathrm{~b}$ e $7 \mathrm{~d}$ ), e o da Figura 7e, que utiliza uma máscara protetora durante o processo. Nesse caso, o discente evidenciou a relevância de se empregar Equipamentos de Proteção Individual (EPI).

A inserção da dimensão temporal nas representações dos alunos, isto é, a resposta ao “quando?”, foi observada nas Figuras 9a e 9c, a partir de associações distintas. Na Figura 9a, a análise temporal está centrada no ser humano e no simbolismo e acréscimo textual da sua morte associada à ingestão de alimento com agrotóxico. Na Figura 9c, a dimensão temporal está associada aos efeitos que o uso de agrotóxicos pode causar, como o mostrado, o da eutrofização.

Os resultados mostraram que os participantes da pesquisa possuem conhecimentos sobre os efeitos dos agrotóxicos no organismo humano, ao desenhar um hospital (Figura 8c e Figura 8e). Os problemas causados por agrotóxicos no Brasil preenchem uma vasta lista de agravos à saúde humana e danos ao meio ambiente. Diante da necessidade de sensibilizar e dialogar com os alunos, conforme descrito por Cavalcanti e colaboradores (2010), podemos contextualizar diversos conteúdos de química 
da graduação ao do ensino médio utilizando a temática agrotóxicos.

Moraes e colaboradores (2011) analisam os agrotóxicos como um tema social quando excede os limites do individual, pois o põe como um problema ambiental e de saúde pública, e recomenda sua abordagem nas aulas de química. $\mathrm{O}$ acesso a essas informações podem minimizar o risco de contaminação doméstica. Neste contexto, a utilização de temas sociais, como por exemplo, agrotóxicos, no Ensino da Química é um poderoso mecanismo para auxiliar no desenvolvimento da cidadania, com o incremento de valores éticos, de solidariedade e de compromisso social.

Conscientizar os alunos sobre as implicações da utilização dos agrotóxicos no solo, a partir da relação destes com conceitos de química ensinados na escola, é muito importante, tanto para estudantes de regiões agrícolas, que convivem diariamente com esse tipo de produto, quanto para o citadino urbano, proporcionando a aproximação do Ensino de Química com as diferentes realidades que os cercam, perante as quais precisam se relacionar ou se posicionar. 


\section{Considerações finais}

A necessidade de abstração associada a outras dificuldades inerentes ao ensino de tópicos como Química Orgânica tem ocasionado diversas discussões e propostas que promovam a sua aprendizagem. Nessa perspectiva, diversas estratégias de ensino acessíveis ao professor e, em muitos casos, possíveis de serem aplicadas na sala de aula, têm sido recomendadas com o propósito de favorecer a compreensão mais adequada do assunto. Uma dessas propostas foi a realizada neste trabalho: o uso sociocontextualizado de agrotóxicos para a construção de modelos tridimensionais de suas moléculas.

Consideramos essencial para uma aprendizagem significativa e crítica o desenvolvimento de um diálogo dinâmico e fluido em nossas salas de aula, mediado pela triangulação dos temas sustentabilidade, uso do solo e agrotóxicos, por exemplo, que possam auxiliar na construção de saberes científicos pautados na formação de cidadãos críticos. Toda experiencia-ação realizada propiciou aos envolvidos repensar temas envolvendo a Química em uma perspectiva da Educação Ambiental Crítica.

\section{Referências}

ALMEIDA, A. C.; SILVA, N. C.; CARVALHO, Q. C. Utilização de Modelos Moleculares Versáteis de Baixo Custo na Repre- 
sentação Tridimensional das Cadeias Carbônicas. In: ENCONTRO NACIONAL DE ENSINO DE QUÍMICA, Brasília, 2010. Anais [...]. Brasília: XV ENEQ, Universidade de Brasília, 2010. Disponível em: <http://www.sbq.org.br/eneq/xv/resumos/Ro956-1.pdf>. Acesso em: 02 nov. 2020.

ANVISA. Programa de Análise de Resíduos de Agrotóxicos em Alimentos (PARA). Plano plurianual 2017-202O - Resultados do $1^{\mathrm{o}}$ Ciclo 2017-2018. Disponível em: <http://antigo.anvisa.gov.br/documents/111215/o/Apresentac ao+-+PARA_dez_2019.pdf/6321e6od-5910-4a61-9e3d79a26o2ebafa>. Acesso em: 04 nov. 2020.

BRASIL. Ministério da Ciência, Tecnologia e Inovações. Instituto Nacional de Pesquisas Espaciais. Infoqueima: Boletim Mensal de Monitoramento - Outubro, v. 5, n. 10, p. 1-14, 2020a. Disponível em: $<$ http://queimadas.dgi.inpe.br/queimadas/portal/outrosprodutos/infoqueima/2020_10_infoqueima.pdf $>$. Acesso em: O4 out. 2020.

. Ministério da Ciência, Tecnologia e Inovações. Instituto Nacional de Pesquisas Espaciais. Infoqueima: Boletim Mensal de Monitoramento - Setembro, v. 5, n. 9, p. 1-14, 2020b.

Disponível em: <http://queimadas.dgi.inpe.br/queimadas/portal/outrosprodutos/infoqueima/2020_09_infoqueima.pdf $>$. Acesso em: O4 out. 2020.

Ministério da Ciência, Tecnologia e Inovações. Instituto Nacional de Pesquisas Espaciais. Infoqueima: Boletim Mensal de Monitoramento - Agosto, v. 5, n. 8, p. 1-15, 2020c. Disponível em: $<$ http://queimadas.dgi.inpe.br/queimadas/portal/outros- 
produtos/infoqueima/2020_08_infoqueima.pdf $>$. Acesso em: 04 out. 2020.

CAVALCANTI, J. A.; FREITAS, J. C. R.; MELO, A. C. N.; FREITAS FILHO, J. R. Agrotóxicos: Uma temática para o Ensino de Química. Revista Química Nova na Escola, v.32, n. 1, 2010.

CHASSOT, A. I. Catalisando transformações na educação. 3 ed. Ijuí: Unijuí, 1993.

DA SILVA, K. S.; DA FONSECA, L. S.; DE FREITAS, J. D. Uma Breve História da Geometria Molecular sob a Perspectiva Didático-Epistemológica de Guy Brousseau. Acta Scientiae, v. 20, n. 4, p. 626-647, 2018.

DE AZEVEDO, A. R. S.; MASCARENHAS, S. A. N. Educação ambiental como política de enfrentamento às queimadas no município de Humaitá, Amazonas, Brasil. Revista EDUCAmazônia, v. 24, n. 1, p. 274-286, 2020.

DE SOUSA, C. T. C.; BASTOS, A. T. Queimadas no Brasil e o direito ao meio ambiente ecologicamente equilibrado. Revista Científica Intr@ciência, 2020. Disponível em: $<$ http://uniesp.edu.br/sites/_biblioteca/revistas/2020052211 5203.pdf>. Acesso em: 03 out. 2020.

EMBRAPA. Empresa Brasileira de Pesquisa Agropecuária Ministério da Agricultura, Pecuária e Abastecimento. Circular Técnica 141. Disponível em: < Embrapa.br/manejo-integradode-pragas-estrategias-e-taticas-de-manejo-para-o-controle-deinsetos-e-acaros-praga-em-hortalicas $>$. Acesso em: o3 out. 2020. 
FREIRE, P. Pedagogia da Autonomia: saberes necessários à prática educativa. Editora Paz e Terra, São Paulo, 1996, 41 ${ }^{\text {a }}$ impressão, 2010.

GERPE, R. L., TAMIASSO-MARTINHON, P., MIRANDA, J. L. Agrotóxicos no cotidiano de sala de aula: estudo da representação imagética no ensino de química. I workshop educação ambiental e o ensino de química - WEAQ. UFRJ, RJ, junho 2019, 2019a.

. Estudos da percepção social da sustentabilidade do uso do solo no ensino de química e biologia. XII Encontro Nacional de Pesquisa em Educação em Ciência, junho de 2019, Natal- RN, 2019b.

. Contextualizando a educação ambiental sobre Pilhas e baterias com cordel cientifico na EJA. II Encontro Regional de Ensino de Química- REQ - UERJ, Resende. Rio de Janeiro, outubro de 2019, 2019c.

- O uso da experimentação na contextualização do ensino de química. XVII encontro regional da SBQ - Rio. CCMN - UFRJ. dezembro de 2019, 2019 d.

IPEA. Instituto de Pesquisa Econômica e Aplicada. Nota Técnica n. 65. Crescimento do uso de agrotóxicos: uma análise descritiva dos resultados do censo agropecuário, 2017. Disponível

em:

<https://www.ipea.gov.br/portal/images/stories/PDFs/nota tecnica/200429_nt_disoc_n65.pdf >. Acesso em: 04 out. 2020, 2020 .

IPEA. Agrotóxicos no Brasil: padrões de uso, política da regulação e prevenção da captura regulatória. Instituto de Pesquisa Econômica e Aplicada. Disponível em:< 
http://repositorio.ipea.gov.br/bitstream/11058/9371/1/td_25 o6.pdf $>$. Acesso em 18 de dezembro de 2020. 2020b.

INPE. Instituto Nacional de Pesquisas Espaciais. Programa Queimadas. Monitoramento dos Focos Ativos por Bioma, 2020. Disponível em: <http://queimadas.dgi.inpe.br/queimadas/portalstatic/estatisticas_estados/>. Acesso em: 04 out. 2020.

MIRANDA, J. L.; BERENDONK, M. Resíduos sólidos e educação ambiental: desafios na busca da transdisciplinaridade. In: Ensino de Química em Revista: o papel social do ensino de química. 1ed. Rio de Janeiro: Instituto de Química - UFRJ, 1, 133-145, 2017.

; O Antropoceno, a Educação Ambiental e o Ensino de Química. Revista Virtual de Química, v. 10, n. 6, 2018.

; BERENDONK, M.; ABREU, T. A arte no lixo. In: Coelho, F. J. F.; Martinhon, P. T.; Sousa, C. (org.). Educação em Ciências, Saúde e Extensão Universitária. 1 ed. Rio de Janeiro: Brazil Publishing, 1, 49-60, 2019.

; GERPE, R. L.; GOMES, F.; BERENDONK, M.; ROCHA, G. S.; MARTINHON, P. T. O contexto dos catadores de material reciclado durante a COVID-19 no Brasil: reflexões cruzadas sob as ópticas de Paulo Freire e Edgard Morin. In: Coelho, F. J. F.; MEIRELLES, R. M. S. C. (Org.). Ensino de Biociências, Meio Ambiente e Saúde. 1ed. Rio de Janeiro: Brazil Publishing, 133-151, 2020.

MORIN, E. Epistemologia da complexidade. In: SCHNITMAND, D. Novos paradigmas, cultura e subjetividade. Porto Alegre: Artmed, p. 189-220, 1996. 
. Os sete saberes necessários à educação do futuro. São Paulo: Cortez; Unesco, 2001.

MORAES, P. C.; TRAJANO, S. C. S.; MAFFRA, S. M.; MESSEDER, J. C. Abordando agrotóxico no ensino de química: uma revisão. Revista Ciências \& Ideias, v. 3, n. 1, p. 1-15, 2011.

SANTOS, W. L. P.; SCHNETZLER, R. P. Função Social: o que significa ensino de química para formar cidadão? Química Nova na Escola, n. 4, 1996.

SILVA; B. M. M.; SANTOS; M. A.; SIMÕES, A. S. M. Construção de um modelo molecular para o ensino de geometria molecular utilizando jujubas. IV Congresso Nacional de Educação, 2017.2 Disponível em: https://editorarealize.com.br/editora/anais/conedu/2017/TR ABALHO_EVo73_MD4_SA16_ID4660_10092017195035.pdf. Acesso em 10 de dezembro de 2020.

SILVA, E. A. S.; DA SILVA, U. A. R.; ESTEVAM, I. H. S.; DAS VIRGENS, C. F. Construção e emprego de modelos do tipo bola e imã para visualização tridimensional de estruturas moleculares em sala de aula. Brazilian Journal of Development, v. 5, n. 6, p. 7381-7392, 2019. 